\title{
Using trip chaining and joint travel as mediating variables to explore the relationships among travel behavior, socio-demographics, and urban form
}

\author{
Yu-Jen Chen \\ The Ohio State University \\ chen.1571@osu.edu
}

\author{
Gulsah Akar \\ The Ohio State University \\ akar.3@osu.edu
}

\begin{abstract}
Using the 2012 Household Travel Survey data for the Cleveland metropolitan area, this study aims to examine the connections between travel behavior by using trip chaining and joint travel as mediating variables of travel distances and controlling for sociodemographics and urban form. Trip chaining and joint travel capture the complexity of tours and intra-household interactions, respectively. Socio-demographics represent personal and household characteristics. Urban form, which is measured not only at tour origins but also at tour destinations, helps capture the effects of residential density, retail and non-retail densities, transportation connectivity, public transit accessibility, and land-use mix. Structural equation model (SEM) approaches are applied to examine the interrelationships among these variables. The model results reveal that significant effects with expected signs exist among travel behavior: Trip chaining is negatively associated with joint travel and positively related to travel distances, and joint travel has negative effects on travel distances. Consistent with existing literature, socio-demographic attributes are strong explanatory factors of travel behavior. Urban form characteristics have significant influence on travel distances at both tour origins and destinations. The findings of this study will improve the future evaluation of transportation projects and land-use policymaking.
\end{abstract}

Keywords: Trip chaining, joint travel, travel distances, urban form

\section{Article history:}

Received: January 25, 2016

Received in revised form: May

20, 2016

Accepted: September 12, 2016

Available online: April 21, 2017

\section{$1 \quad$ Introduction}

Increasing attention in recent years has been given to research of travel behavior. Outcomes of travel behavior, primarily in terms of travel distances and vehicle miles traveled (VMT), have been viewed as main contributors to greenhouse effects, energy consumption, environmental quality, traffic congestion, and traffic accidents (Akar, Chen, \& Gordon, 2016; Brownstone \& Golob, 2009; Rentziou, Gkritza, \& Souleyrette, 2012). In addition, travel distances and travel demand are associated with

Copyright 2017 Yu-Jen Chen \& Gulsah Akar

http://dx.doi.org/10.5198/jtlu.2017.882

ISSN: 1938-7849 | Licensed under the Creative Commons Attribution - Noncommercial License 3.0

The Journal of Transport and Land Use is the official journal of the World Society for Transport and Land Use (WSTLUR) and is published and sponsored by the University of Minnesota Center for Transportation Studies. 
activity-travel patterns such as trip chaining and joint travel (Bricka, 2008; Duncan, 2015; Vovsha, Peterson, \& Donnelly, 2003). Given the fact that the transportation system is related to negative externalities, planners and policymakers try to control and manage the activity-travel patterns and travel distances (Van Acker \& Witlox, 2010). Trip chaining is commonly defined as a home-based tour that connects multiple out-of-home activities (Primerano, Taylor, Pitaksringkarn, \& Tisato, 2008). Investigating the mechanism and consequences of trip chaining improves understanding of links between activity participation and mobility (Noland \& Thomas, 2007; Yang, Wang, Ren, Fan, Qi, \& Chen, 2010; Ho \& Mulley, 2013a; Ho \& Mulley, 2013b; Vovsha et al., 2003). Researchers investigating joint travel find that joint tours represent a substantial percentage (around 40 to 50 percent) of total home-based tours in many metropolitan areas, such as in Ohio and New York in the United States and Sydney in Australia (Ho \& Mulley, 2013a; Vovsha et al., 2003). Therefore, research about joint travel can improve the evaluation of transportation policies and their implementations such as high occupancy vehicle lanes and high occupancy toll lanes (Srinivasan $\&$ Bhat, 2008; Vovsha et al., 2003). Trip chaining and joint travel are generally identified as measurements of tour complexity, intra-household interactions, and spatial-temporal constraints in travel behavior studies (Chandrasekharan \& Goulias, 1999; Ho \& Mulley, 2013a; Noland \& Thomas).

Many studies have regarded trip chaining, joint travel, and travel distances as different aspects of travel behavior to be explained by various factors, including socio-demographics and urban form (Akar et al., 2016; Ewing \& Cervero, 2001; Ewing \& Cervero, 2010). However, limited work has been done to use activity-travel patterns as mediating variables and analyze how trip chaining and joint travel shape the resulting travel distances. Furthermore, relationships between travel behavior and built environment at out-of-home activity locations remains unclear. By using 2012 household travel survey data of the Cleveland metropolitan area, this study aims to fill this gap by achieving the following research objectives: (i) investigate the interconnections among trip chaining, joint travel, and resulting travel distances; (ii) use socio-demographics and urban form at tour origins and destinations as exogenous variables to explain activity-travel patterns and travel distances; (iii) estimate the mediating effects of socio-demographics and urban form via trip chaining and joint travel on travel distances.

The paper is structured as follows. Section 2 reviews previous research on trip chaining, joint travel, and travel distances. Section 3 describes the conceptual framework and the structural equation model (SEM) used in this study. Datasets and variables used in this study are summarized in Sections 4, 5, and 6. Section 7 provides model results and relevant discussions. Section 8 concludes with important findings and future research directions.

\section{$2 \quad$ Literature review}

A tremendous amount of research has tried to explain travel behavior (trip chaining, joint travel and travel distances) using socio-demographics and urban form. This section briefly summarizes the previous studies.

\section{$2.1 \quad$ Trip chaining}

A number of definitions of trip chaining have been developed during past decades (Holzapfel, 1986; McGuckin \& Murakami, 1999). Based on the studies that Primerano, Taylor, Pitaksringkarn, and Tisato (2008) review, trip chaining is used to link secondary activities to a primary activity through trips, which begin and end at home. Empirical studies usually use trip chaining to measure the tour complexity in terms of number of activity stops or number of trip segments within the tour (Liu, 2012; Noland \& Thomas, 2007; Wang, 2014; Yang et al., 2010). 
Among the personal characteristics, gender, travelers' age, and employment status are important determinants of trip chaining (Bhat, 1997; Kitamura \& Susilo, 2005; Liu, 2012; McDonald, 2005; McGuckin \& Murakami, 1999; Noland \& Thomas, 2007; Susilo \& Kitamura, 2008; Yang et al., 2010). Such studies find that women, elderly, and workers tend to chain more trip segments. Household income and the presence of children in the household have positive impacts on trip chaining (Antipova \& Wang, 2010; Bhat, 1997; Kitamura \& Susilo, 2005; Krizek, 2003; Liu, 2012; Lu \& Pas, 1999; Schmöcker, Su, \& Noland, 2010; Susilo \& Kitamura, 2008; Van Acker \& Witlox, 2011; Wang, 2014). On the other hand, increasing household size and vehicles per worker decrease the tendency of trip chaining (Bricka, 2008; Kitamura \& Susilo, 2005; Susilo \& Kitamura, 2008; Van Acker \& Witlox, 2011; Wallace, Barnes, \& Rutherford, 2000).

Several studies have revealed that the built environment of residential locations has significant influence on trip chaining. For instance, people living in the low population density neighborhoods tend to make more complex trip chaining (Noland \& Thomas, 2007; Bricka, 2008). Kitamura and Susilo (2005) suggest that non-workers residing in suburban areas tend to chain less trip segments. Frank, Bradley, Kavage, Chapman, and Lawton (2008) show that higher presence of shops and services where travelers live and work is associated with reduction of activity stops within commute tours.

\section{$2.2 \quad$ Joint travel}

The interest of studying joint travel has been raised by the recognition that an individual's activity-travel decision is not isolated but affected by the other household members (Ho \& Mulley, 2013b). Chandrasekharan and Goulias (1999) find that households with only one vehicle may be motivated to pursue joint trips, and households with children are more likely to travel jointly. Vovsha et al. (2003) conclude that full-time workers are more likely to travel alone and pre-driving-age people are more likely to make joint travel.

More recently, Lin and Wang (2014) address that households with children have more joint activities and travel. Their study also suggests that household income has positive impacts on traveling with family members. Households' life-cycle stages and children's attributes, such as the presence of children in households and the age of the youngest child, influence parents' activity-travel patterns significantly (McDonald, 2005; McDonald, 2006; Sun, Waygood, Fukui, \& Kitamura, 2009; Tillberg Mattsson, 2002; Waygood, 2011). Multiple studies indicate that children at different ages impose different constraints on joint travel patterns as children's ages increase, the burden of adult chauffeuring and supervision decreases (Ho \& Mulley, 2015; Vovsha et al., 2003; Vovsha \& Petersen, 2005).

Existing literature reports the potential influence of urban form factors on joint travel decisions, yet empirical evidence is limited. For example, Vovsha et al. (2003) find people living in urban areas have a higher tendency to travel together.

\subsection{Travel distances}

Previous research links socio-demographics, trip characteristics, and built environment to travel distances. Women are found to travel shorter distances than men (Akar et al., 2016; Elldér, 2014; Mercado \& Páez, 2009). The elderly travel less frequently and when they do, they cover shorter distances (Akar et al., 2016; Elldér, 2014; Mercado \& Páez, 2009; Schmöcker, Quddus, Noland, \& Bell, 2005). Having a driver's license increases travel distances (Akar et al., 2016; Mercado \& Páez, 2009; Morency, Páez, Roorda, Mercado, \& Farber, 2011; Schmöcker et al, 2010). Workers travel longer distances than the counterparts do (Akar et al., 2009; Liu, 2012; Mercado \& Páez; Schmöcker et al., 2009). People with higher education levels tend to travel longer distances (Akar et al., 2009; Dieleman, Dijst, \& Burghouwt, 
2002). Household income and vehicle ownership increase travel distances (Akar et al., 2009; Dieleman et al., 2002; Elldér, 2014; Liu; Schmöcker et al., 2005).

As built environment has been shown to influence travel distances significantly, land-use patterns around residential neighborhoods are widely examined and reviewed in existing studies (Ewing \& Cervero, 2001; Ewing \& Cervero, 2010). For instance, Dieleman, et al. (2002) report that people living in suburbs or rural areas travel longer distances. As compared to living in the non-urban areas, Elldér (2014) shows that people who live in medium to large urban areas travel longer distances. Akar et al. (2016) find that travel distances increase for those who live in the areas with higher percentage of single detached housing units and lower densities in population, employment, and intersections. Mercado and Páez (2009) conclude that high mix of commercial and residential areas is negatively associated with travel distances.

Despite the fact that a considerable amount of literature has been using socio-demographics and urban form to explain different travel behavior indicators, the empirical work of examining the effects of activity-travel patterns on the resulting travel distances is limited. In addition, the effects of land-use patterns at out-of-home activity locations on travel behavior are unclear. This paper aims at investigating the interconnections among the travel behavior indicators by using trip chaining and joint travel as mediators of travel distances. The effects of built environment are examined not only at tour origins but also at tour destinations.

\section{Conceptual framework and methodology}

\subsection{Conceptual framework}

Figure 1 illustrates the relationships between socio-demographics, urban form, and travel behavior in this study. This study uses home-based tour as the basic unit of analysis. Based on the literature review, it is reasonable to hypothesize that personal and household socio-demographics, along with urban form at tour origins and destinations affect trip chaining, joint travel, and travel distances. Since travel is a derived demand of undertaking activities (Kitamura, 1988), this study postulates that individuals' decisions of whether or not to travel with other household members depend on the activities that they participate in. Therefore, trip chaining is assumed to influence joint travel. Both activity-travel patterns then affect the travel distances for each tour.

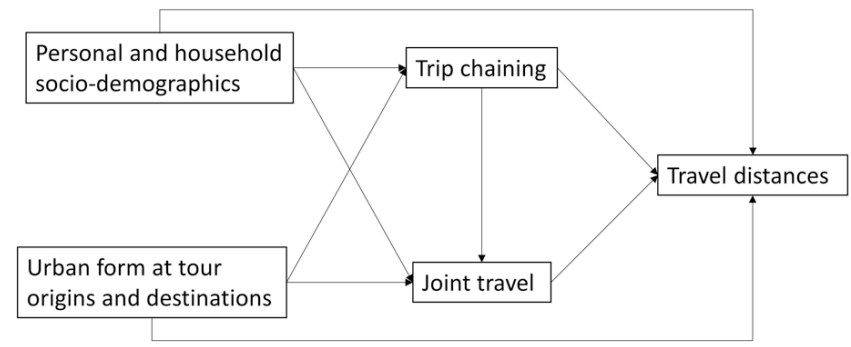

Figure 1: Conceptual framework

\subsection{Structural equation modeling (SEM) and path analysis}

To analyze the interconnections among socio-demographics, urban form, activity-travel patterns, and 
travel distances simultaneously, path analysis is applied in this study. Path analysis is a special case of structural equation modeling (SEM) that only includes measured variables (van den Berg, Arentze, \& Timmermans, 2013). SEM is a statistical technique for estimating causal relations of exogenous variables on endogenous variables using a combination of statistical data and qualitative causal assumptions (Pearl, 2000; Xiao, 2013). SEM can deal with multiple endogenous variables and exogenous variables and examine the interrelationship among variables by estimating the total, direct, and indirect effects. Total effects are the sum of direct effects and indirect effects. Direct effects are defined as the links between exogenous variables and endogenous variables. Indirect effects represent the sum of all the effects of the involved variables (Liu \& Shen, 2011). Kuppam and Pendyala (2001) summarizes that a typical path analysis in structural equation model with " $G$ " endogenous variables can be presented as following matrix equation system in Equation 1:

$$
\left[\begin{array}{c}
Y_{1} \\
Y_{2} \\
\cdot \\
\cdot \\
Y_{G}
\end{array}\right]=\left[\begin{array}{ll}
Y & X
\end{array}\right]\left[\begin{array}{l}
\mathrm{B} \\
\Gamma
\end{array}\right]+\left[\begin{array}{c}
\varepsilon_{1} \\
\varepsilon_{2} \\
\cdot \\
\cdot \\
\cdot \\
\varepsilon_{G}
\end{array}\right]
$$

The above matrix equation system can be rewritten as

$$
Y=(I-B)^{-1}(\Gamma X+\varepsilon)
$$

(or)

$$
Y=B Y+\Gamma X+\varepsilon
$$

Where $\mathrm{Y}$ is a column vector of endogenous variables,

$B$ is a matrix of coefficient associated with right-hand-side endogenous variables,

$X$ is a column vector of exogenous variables,

$\Gamma$ is a matrix of coefficient associated with exogenous variables, and

$\varepsilon$ is a $\mathrm{p} \times 1$ vector of residuals of the endogenous variables.

This paper uses AMOS, which is a software program used to estimate SEM. Given the fact that the data involve non-normal variables, maximum likelihood (ML) estimator with bootstrapping procedure is applied for coefficient estimation (Byrne, 2013).

\section{$4 \quad$ Research design}

\subsection{Data sources}

The primary data used in this study are the 2012 Northeast Ohio Regional Travel Survey data which are collected at the Cleveland metropolitan area (Wilhelm, Wolf, Kang, \& Taylor, 2014). The travel survey data include trip segments and activity location information, along with individuals' personal and household characteristics. The study area comprises the following five counties of Ohio: Cuyahoga County, Geauga County, Lake County, Lorain County, and Medina County. Due to privacy concerns, trip origins and destinations are released at transportation analysis zone (TAZ) level.

The corresponding urban form data in 2012 come from several sources: Census Transportation Planning Products (CTPP), Google General Transit Feed Specification (GTFS), and Topologically Integrated Geographic Encoding and Referencing (TIGER). The urban form variables measure various aspects of the built environment including density, transportation network design, and land-use mix at TAZ level. 


\subsection{Trip chaining and joint travel in the data}

The trip segments in the survey data are combined into home-based tours, which are defined as the sequence of trips starting and ending at an individual's home (Primerano et al., 2008). The number of activity stops that measures the concept of trip chaining is then collected from each home-based tour.

Joint travel is represented by the ratio of joint trip segments to total trip segments for each tour, which captures intra-household interactions and the level of how individuals cooperate the travel with their family members. The value of joint travel ratio for each tour is calculated by the following equation.

$$
\mathrm{RJOINT}_{i}=\frac{\text { Number of joint trip segments in } \text { tour }_{i}}{\text { Total trip segments in the } \text { tour }_{i}} \times 100 \%
$$

Where RJOINT $i$ means the ratio of joint trip segments for a home-based tour $i$

\subsection{Classification of tour types and primary activity for each tour}

As described in the previous section, this study uses urban form variables at tour origins and destinations to explain activity-travel patterns and travel distances. Adopting the definition from Liu (2012), the tour origins are the residential locations and the tour destinations are the locations of primary activities for each tour.

To classify the tours and determine the primary activity locations, all the tours are categorized into three types. The mandatory tours are composed of the trips only for two mandatory activities: work and school. The mandatory-mixed tours consist of trips for mandatory and non-mandatory activities. The non-mandatory tours only include the trips for non-mandatory activities.

Among the three tour categories, the definition of the primary activity for each tour is follows: (1) the primary activity for mandatory tours and non-mandatory tours is the activity with the longest activity duration within the tour, (2) the primary activity for the mandatory-mixed tours is the mandatory activity with longest activity duration.

\section{$5 \quad$ Variables of interest}

Table 1 shows the selected exogenous and endogenous variables in this study. There are three endogenous variables of travel behavior in the model: trip chaining, joint travel, and travel distances.

The exogenous variables include socio-demographic and urban form variables. Gender, age, license ownership, employment status, and transit pass ownership are included as personal characteristics. Household attributes consist of household size, number of household vehicles, household income, presence of children and youngest child's age.

Six built environment variables are included to evaluate the effects of urban form at tour origins and destinations. Densities of residential population, retail employment, non-retail employment, intersections, and bus stops are calculated at the TAZ level (per square mile). In addition, a job-population balance index adopted from Ewing et al. (2011) and Akar et al. (2016) is included in this study. The equation of job-population index is presented as follows.

$$
\text { Job }- \text { population index }{ }_{k}=1-\frac{(\mid \text { employment }-0.7 \times \text { population } \mid)}{(\text { employment }+0.7 \times \text { population })}
$$

Where Job-population index $x_{k}$ means the job-population index for TAZ $k$. The parameter 0.7 represents a balance of employment and population in the study area. 
This index ranging from 0 to 1 captures the balance between employment and residential population. Only jobs or residents exist in the TAZ when the index is close to 0 . On the other hand, the ratio of jobs and residents is optimal from travel behavior perspective when the index value ranges to 1 . The parameter varies based on different empirical facts of existing research. In order to maximize the explanatory power of the variable, Ewing et al. (2011) uses 0.2 and Akar et al. (2016) uses 0.5 in their studies. In this paper, this value is adjusted to 0.7 .

Table 1: Endogenous and exogenous variables used in this study

\begin{tabular}{|c|c|}
\hline Variables & Description \\
\hline \multicolumn{2}{|l|}{ Endogenous Variables } \\
\hline Travel distances & Distances traveled per home-based tour \\
\hline Joint travel & Joint travel ratio per home-based tour \\
\hline Trip chaining & Number of activity stops per home-based tour \\
\hline \multicolumn{2}{|l|}{ Exogenous Variables } \\
\hline \multicolumn{2}{|l|}{ Personal socio-demographics } \\
\hline Female & 1 , if individual is female; 0 , otherwise \\
\hline Age & Age (in years) of individual \\
\hline License status & 1, if individual has a driver's license; 0 , otherwise \\
\hline Employment status & 1 , if individual is employed; 0 , otherwise \\
\hline Transit pass ownership & 1, if individual has transit pass; 0 , otherwise \\
\hline \multicolumn{2}{|l|}{ Household (HH) socio-demographics } \\
\hline $\mathrm{HH}$ size & Number of household members \\
\hline $\mathrm{HH}$ vehicles & Number of household vehicles \\
\hline HH income & Household income (in thousand US dollar) \\
\hline No children presence in $\mathrm{HH}$ & 1, if no child in the household; 0 , otherwise \\
\hline Youngest child's age is up to 5 in $\mathrm{HH}$ & 1 , if the age of youngest child is up to 5 ; 0 , otherwise \\
\hline Youngest child's age is 6 to 10 in $\mathrm{HH}$ & 1 , if the age of youngest child is 6 to $10 ; 0$, otherwise \\
\hline Youngest child's age is 11 to 15 in $\mathrm{HH}$ & 1 , if the age of youngest child is 11 to $15 ; 0$, otherwise \\
\hline Youngest child's age is 16 to 18 in $\mathrm{HH}$ & 1 , if the age of youngest child is 16 to 18 ; 0 , otherwise \\
\hline \multicolumn{2}{|c|}{ Urban form variables (for tour origins and destinations at TAZ level) } \\
\hline Residential density & Residential population per square mile \\
\hline Retail density & Retail employment per square mile \\
\hline Non-retail density & Non-retail employment per square mile \\
\hline Intersection density & Number of intersection nodes per square mile \\
\hline Bus stop density & Number of bus stops per square mile \\
\hline Job-population index & $\begin{array}{l}\text { Index that measures the employment and population } \\
\text { balance }\end{array}$ \\
\hline
\end{tabular}

\section{Descriptive analysis}

For the interest of this study, tours from households with one person are dropped from the dataset as these households would not generate joint trips with members from the same household. After data screening and cleaning, the sample data used for analysis consist of 7,398 tours, which are made by 4,655 individuals from 2,442 households within five counties of the Cleveland area. Table 2 summarizes the descriptive statistics of the sample data. Among all the tours, the average travel distances are 17.23 miles; the mean of activity stops for each tour is 2.43 ; and around $25 \%$ of trip segments within each tour are made jointly. Women are slightly more represented in the sample data than men. Around $90 \%$ of participants have driver licenses, $7 \%$ of travelers are transit pass owners, and nearly $60 \%$ of survey respondents are employed. The average household size is around 3, each household has two vehicles on 
average, and the average annual household income is around $\$ 70,000$. About $65 \%$ of households do not have any children, $10 \%$ of households have a child 5 years of age or younger, $7 \%$ of households' youngest child is between the ages of 6 and 10,13\% of the households' youngest child is between the ages of 11 and 15, and 7\% of households' youngest child is between the ages of 16 and 18 . Figure 2 demonstrates the study area, which includes Cuyahoga, Geauga, Lake, Lorain and Medina Counties of the Cleveland area. The tour origins and destinations are presented at the centroids of the TAZs.

Table 2: Descriptive statistics of sample data

\begin{tabular}{|c|c|c|c|}
\hline & Sample Percentage & Mean & Std. Dev. \\
\hline \multicolumn{4}{|l|}{ Travel behavior for each tour } \\
\hline Travel distances (miles) & & 17.23 & 17.93 \\
\hline Trip chaining (number of activity stops) & & 2.43 & 1.91 \\
\hline Joint travel (ratio of joint trip segments) & & 24.83 & 39.45 \\
\hline \multicolumn{4}{|l|}{ Personal socio-demographics } \\
\hline \multicolumn{4}{|l|}{ Gender } \\
\hline Female & $51.9 \%$ & & \\
\hline Age & & 49.94 & 17.45 \\
\hline Has driver's license & $88.37 \%$ & & \\
\hline Has transit pass & $7.39 \%$ & & \\
\hline Employed & $58.02 \%$ & & \\
\hline \multicolumn{4}{|l|}{ Household socio-demographics } \\
\hline Household size & & 2.87 & 1.19 \\
\hline Number of household vehicles & & 2.02 & 1.05 \\
\hline Household income (in thousand) & & 68.16 & 48.32 \\
\hline No children presence in household & $65.27 \%$ & & \\
\hline Youngest child's age up to 5 in household & $9.75 \%$ & & \\
\hline Youngest child's age 6 to 10 in household & $7.58 \%$ & & \\
\hline Youngest child's age 11 to 15 in household & $10.73 \%$ & & \\
\hline Youngest child's age 16 to 18 in household & $6.67 \%$ & & \\
\hline
\end{tabular}

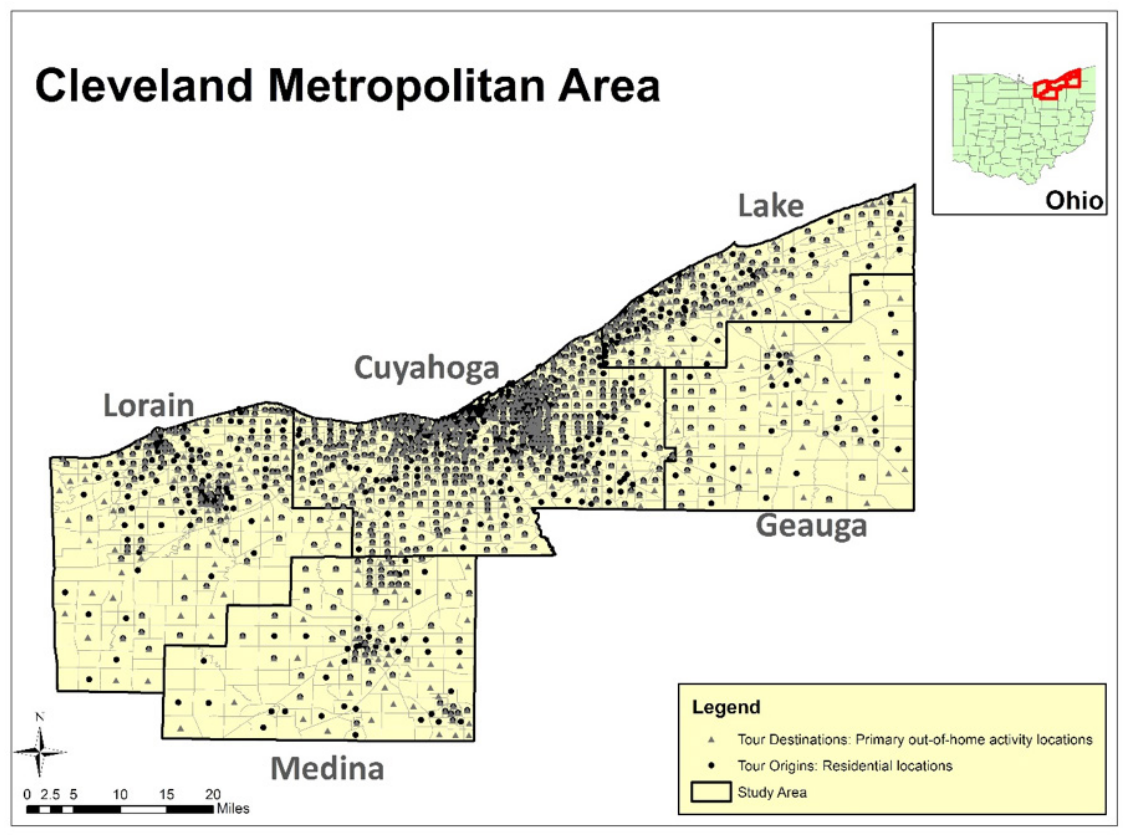

Figure 2: Study area: the Cleveland Metropolitan Area 


\section{$7 \quad$ Results}

This section provides the overall model fit and effects of exogenous and endogenous variables. First, model fit is discussed and several fit indices are demonstrated. Then the effects of endogenous variables are presented. The direct effects of exogenous variables are shown, which indicate how socio-demographics and urban form affect travel behavior directly. Finally, the indirect and total effects of exogenous variables are discussed. Using activity-travel patterns as mediators, the indirect effects of the exogenous variables specify the effects channeled via the activity-travel patterns on travel distances. The total effects are the results of direct effects and indirect effects. All the coefficients are examined but only the coefficients with p-value less than 0.1 are shown in Table 3.

\subsection{Model fit}

The model has $\chi^{2}$ of 20.212 with 32 degrees of freedom corresponding to a probability of 0.947 . This implies the model fits the data very well and cannot be rejected. The ratio of $\chi^{2}$ and degrees of freedom is 0.632, which is an indicator of good fit (Schermelleh-Engel et al., 2003). Other measures of fit, such as root-mean-square error of approximation (RMSEA $=0.001)$, comparative fit index (CFI=0.99), and standardized root mean square residual $(\mathrm{SRMR}=0.003)$ are found to be acceptable by model fit criteria for SEM (Mueller \& Hancock, 2010; Hu \& Bentler, 1999).

\subsection{Effects among endogenous travel behavior}

According to the direct effects among endogenous variables in Table 3, all direct effects among travel behavior are statistically significant. Trip chaining is negatively associated with joint travel. This means increasing the complexity of tours may decrease the tendency of sharing the same travel patterns with other family members. Trip chaining is positively associated with travel distances. This may indicate that as tours become more complex, the travelers are likely to take indirect routes to the tour destinations. All else being equal, joint travel is negatively related to travel distances. The results show that the tours with higher joint travel ratio are more likely to be shorter. One possible reason is that traveling longer distances with other household members may require more spatial-temporal coordination as compared to traveling shorter distances. It can also be explained by the fact that tours with high joint travel ratio tend to be local tours, such as chauffeuring children to school. The standardized total effects of two activity-travel patterns suggest that trip chaining has stronger effects on travel distances than joint travel.

\subsection{Direct effects of exogenous socio-demographics on endogenous travel behavior}

Table 3 shows that most socio-demographics have significant impacts on travel behavior. Women are more likely to travel with other household members. Being female is negatively associated with travel distances. This finding indicates that women make shorter home-based tours then men, which is consistent with the previous findings (Akar et al., 2016; Elldér, 2014; Mercado \& Páez, 2009).

Age poses a negative influence on trip chaining, showing that older people tend to make simple tours. The possession of a driver's license is negatively correlated with trip chaining. The interpretation of this finding could be combining multiple trip segments is not compulsory for licensed individuals. The ownership of a driver's license is negatively associated with joint travel. This may be because people without driver's licenses are more reliant on those with licenses in a car-favorable environment. Consistent with existing research, the driver's license ownership is positively related to travel distances (Akar et al., 2016; Mercado \& Páez, 2009; Morency et al., 2011; Schmöcker et al., 2005). The model results sug- 
gest that people who have a transit pass are inclined to make complex tours. This is probably due to the fact that transit pass owners have higher propensity to utilize park-and-ride facilities. In addition, transit pass owners tend to rely on public transit more, which may require more transfers. Susilo and Kitamura (2008) argue that transit commuters have greater propensity to visit non-work places near transit stops on their commute routes. The transit pass owners are less likely to travel with their family members. This could be explained by the fact that the owners have more choices and fewer constraints when traveling.

Consistent with the findings of Lin and Wang (2014), the negative effects of being employed on joint travel reveal that workers have higher propensity of traveling alone. The fewer intra-household interaction in terms of traveling may due to workers' less flexible daily schedules. On the other hand, supporting the existing literature (Akar et al., 2016; Liu, 2012; Mercado \& Páez, 2009; Schmöcker et al., 2005), workers may be inclined to travel longer distances.

Looking at the direct effects of household attributes, one can see that the household size is negatively associated with trip chaining and travel distances. Similar to the findings of Kitamura and Susilo (2005) and Susilo and Kitamura (2008), people from larger households tend to make shorter and simpler tours. Wallace et al. (2000) indicates that larger households may have greater number and variety of destinations, which decrease the tendency of making complex tours.

As anticipated, the positive effects of household size on joint travel show as household size increases, individuals are more likely to travel with their family members. Number of vehicles affects travel distances positively and joint travel negatively. The interpretation of this finding could be that the household vehicles are treated as a resource constraint for traveling. The household income has negative impacts on trip chaining, implying that household income may also be viewed as a resource constraint while combining trip segments. In agreement with previous studies (Akar et al., 2016; Dieleman et al., 2002; Elldér, 2014; Schmöcker et al., 2005), household income is found to be positively related to travel distances. The presence and age of children in households are influential factors for joint travel. Compared to households without children, households with the youngest child between 11 and 15 tend to generate more joint trips. This is consistent with the previous studies (Vovsha et al., 2003; Ho \& Mulley, 2015), which found that the needs for adult supervision and chauffeuring for children in these households are higher than the counterpart.

\subsection{Direct effects of exogenous urban form variables on travel behavior}

The model results demonstrate that the urban form measurements influence the travel behavior at tour origins (i.e., residential locations) as well as at tour destinations (i.e., primary activity locations). Residential density at tour origins and destinations negatively affect travel distances, meaning that the tours people take from and to compact residential areas tend to be short. Furthermore, high resident density in residence neighborhood is found to increase the tour complexity, which is constant with Kitamura and Susilo (2005).

The retail density at tour destinations is positively associated with joint travel. This implies that people may tend to travel jointly when their primary activities are located in retail intensive areas. At tour origins, it is reasonable to see that the effects of retail density and non-retail density on activity-travel patterns are opposite. The retail density influences trip chaining and joint travel negatively, whereas the non-retail density affects both of the activity-travel patterns positively.

Intersection density and bus stop density capture the street connectivity and public transit accessibility respectively. The results show that the increasing intersection density at tour destinations decreases joint travel. As expected, the intersection density at tour origins is negatively correlated with travel distances, implying that people live in better transportation network areas are more likely to make shorter tours. Increasing bus stop density at tour destinations increases the trip chaining and travel distances. 
This finding may imply that people traveling to the areas with more available travel modes are more apt to make complex tours and travel further.

The job-population index has negative effects on travel distances at both tour destinations and origins. On the other hand, this index has positive effects on joint travel at tour destinations and origins. People are more likely to travel together with their family members and make shorter tours if they live in or travel to a neighborhood with a balance of employment and population, such as commercial and residential mix areas.

\subsection{Indirect effects of exogenous variables on travel distances}

Table 3 also includes the indirect effects of exogenous variables on travel distances. This research uses activity-travel patterns (trip chaining and joint travel) as the mediating variables of the resulting travel distances. While some of the indirect effects are channeled through either one of the patterns, others are channeled via both. For example, the indirect effects of being female on travel distances are due to the effects on the joint travel and channeled via joint travel. The direct effects of being female on joint travel are positive, but because joint travel influences travel distances negatively, it decreases the indirect effects of being female on travel distances. That is, being female may indirectly bring about a decrease in travel distances by increasing the propensity of joint travel. Another example is that the negative indirect effects of household size on travel distances are channeled via both activity-travel patterns and can be decomposed into three parts. The first part is on trip chaining and channeled via trip chaining. The second part is on joint travel and channeled via joint travel. The last part is on trip chaining and channeled through trip chaining and joint travel. It means that increasing household size is expected to decrease the travel distances indirectly through the channel of the activity-travel patterns.

Most of the indirect effects of urban form at tour destinations and origins are statistically significant. It is interesting to note that some urban form variables only affect the travel distances indirectly through the activity-travel patterns. For instance, the retail density at tour destinations only has negative indirect effects on the travel distances. On the other hand, the increasing non-retail density at tour origins increases the travel distances indirectly through the activity-travel patterns. These findings indicate that retail density at tour destinations and non-retail density at tour origins may not affect travel distances directly, but may have indirect effects on the travel distances caused by trip chaining or joint travel.

\subsection{Total effects of exogenous variables on travel distances}

The total effects are calculated by adding the direct effects and indirect effects and are included in Table 3. All the total effects of exogenous variables keep the same signs as the corresponding direct effects or indirect effects. Most of the socio-demographic variables affect travel distances significantly at 95 percent confidence level. The magnitude of standardized total effects helps determine which of variables have a greater effect on travel distances. The results suggest that employment status is the strongest personal characteristics affecting travel distances. Among household attributes, household size influences travel distances the most.

Except intersection density at tour destinations, all total effects of urban form at tour origins and destinations on travel distances are statistically significant. Furthermore, residential density, non-retail density, bus stop density, and job-population index affect travel distances at tour destinations more than they do at tour origins. This finding indicates significant influences of urban form on travel distances exist not only at residential locations but also at primary out-of-home activity locations. According to the results, travel distances are influenced by bus stop density and job-population index the most at tour destinations and by intersection density the most at tour origins. 
Table 3: Model estimation results for travel behavior, socio-demographics, and urban form factors (standardized effects)

\begin{tabular}{|c|c|c|c|c|c|c|c|c|}
\hline & \multicolumn{3}{|c|}{ Travel distance } & \multicolumn{3}{|c|}{ Joint travel } & \multicolumn{2}{|c|}{ Trip chaining } \\
\hline Types of Effects & Total & Indirect & Direct & Total & Indirect & Direct & Total & Direct \\
\hline \multicolumn{9}{|c|}{ Endogenous variables: Activity Travel Patterns } \\
\hline Joint travel & -0.025 & & -0.025 & & & & & \\
\hline Trip chaining & 0.435 & 0.001 & 0.435 & -0.024 & & -0.024 & & \\
\hline \multicolumn{9}{|c|}{ Exogenous variables: Personal Socio-demographics } \\
\hline Female & -0.043 & -0.001 & -0.042 & $\mathbf{0 . 0 3 7}$ & & $\mathbf{0 . 0 3 7}$ & & \\
\hline Age & -0.014 & -0.014 & & 0.001 & 0.001 & & -0.032 & -0.032 \\
\hline Driver's license ownership & 0.038 & -0.02 & 0.058 & -0.031 & 0.001 & -0.032 & -0.048 & -0.048 \\
\hline Transit pass ownership & 0.026 & 0.026 & & -0.023 & -0.001 & -0.022 & 0.059 & 0.059 \\
\hline Employed status & 0.120 & 0.013 & 0.106 & -0.134 & $-0.001^{a}$ & -0.133 & $0.023^{\mathrm{a}}$ & $0.023^{\mathrm{a}}$ \\
\hline \multicolumn{9}{|c|}{ Exogenous variables: Household Socio-demographics } \\
\hline Household size & -0.082 & -0.024 & -0.058 & 0.107 & 0.001 & 0.106 & -0.049 & -0.049 \\
\hline Household income & 0.026 & -0.016 & 0.042 & 0.001 & 0.001 & & -0.038 & -0.038 \\
\hline Household vehicle & 0.046 & 0.003 & 0.043 & -0.134 & & -0.134 & & \\
\hline \multicolumn{9}{|l|}{ No children presence (base case) } \\
\hline \multicolumn{9}{|l|}{ Youngest child's age up to 5} \\
\hline \multicolumn{9}{|l|}{ Youngest child's age 6 to 10} \\
\hline Youngest child's age 11 to 15 & $-0.001^{a}$ & $-0.001^{\mathrm{a}}$ & & 0.026 & & 0.026 & & \\
\hline \multicolumn{9}{|l|}{ Youngest child's age 16 to 18} \\
\hline \multicolumn{9}{|c|}{ Exogenous variables: Urban form at tour destinations } \\
\hline Residential density & -0.057 & & -0.057 & & & & & \\
\hline Retail density & -0.001 & -0.001 & & 0.036 & & 0.036 & & \\
\hline Non-retail density & 0.064 & & 0.064 & & & & & \\
\hline Intersection density & $0.030^{\mathrm{a}}$ & 0.001 & $0.028^{\mathrm{a}}$ & -0.058 & & -0.058 & & \\
\hline Bus stop density & 0.066 & $\mathbf{0 . 0 2 3}$ & 0.043 & -0.001 & -0.001 & & 0.054 & 0.054 \\
\hline Job-population index & -0.066 & -0.001 & -0.065 & 0.028 & & 0.028 & & \\
\hline \multicolumn{9}{|c|}{ Exogenous variables: Urban form at tour origins } \\
\hline Residential density & -0.041 & 0.014 & -0.056 & -0.001 & -0.001 & & 0.033 & $\mathbf{0 . 0 3 3}$ \\
\hline Retail density & -0.047 & -0.025 & $-0.022^{\mathrm{a}}$ & -0.057 & 0.001 & -0.059 & -0.061 & -0.061 \\
\hline Non-retail density & 0.018 & 0.018 & & 0.039 & -0.001 & 0.040 & 0.044 & 0.044 \\
\hline Intersection density & -0.053 & & -0.053 & & & & & \\
\hline Bus stop density & -0.037 & $0.001^{\mathrm{a}}$ & -0.038 & $-0.024^{\mathrm{a}}$ & & $-0.024^{a}$ & & \\
\hline Job-population index & -0.043 & -0.001 & -0.042 & 0.029 & & 0.029 & & \\
\hline
\end{tabular}

Coefficients in bold type are statistically significant at the $95 \%$ level

${ }^{a}$ Coefficients are statistically significant at the $90 \%$ level

\section{Conclusion}

Previous studies on travel behavior consider trip chaining, joint travel, and travel distances as different aspects of travel behavior and aim to explain these using a variety of factors, such as socio-demographics and urban form. Using the 2012 travel survey data of the Cleveland metropolitan area, this study aims to investigate how activity-travel patterns shape the resulting travel distances and analyze how sociodemographics and urban form factors affect travel behavior simultaneously. In this study, the effects of built environment are measured at tour origins and as well as tour destinations to unravel the different effects of residential locations and primary out-of-home activity locations. SEM approaches are applied to disentangle the interactions among the endogenous and exogenous variables. The remarks and future 
research directions are summarized as follows.

Since travel demand is derived from participating in out-of-home activities, this study assumes that the number of activities (trip chaining) affects the ratio of joint trip segments (joint travel) for each home-based tour. Both activity-travel patterns then influence the resulting travel distances. The model results suggest that the trip chaining is negatively associated with joint travel and positively related to travel distances. On the other hand, joint travel is negatively related to travel distances, implying that people may travel jointly for shorter tours as there may be fewer spatial-temporal constraints involved.

As expected, the overall model shows that most socio-demographic attributes have significant effects on travel behavior. Besides, all indirect effects of personal socio-demographics mediated by activitytravel patterns on travel behavior are significant. Among socio-demographic characteristics, employment status is found to be the strongest factor affecting travel distances and joint travel, while transit pass ownership influences trip chaining the most.

The model results show that urban from affects travel distances significantly. First, the total effects suggest that urban form factors at tour origins (residential locations), as well as at destinations (primary activity locations), play important roles on influencing travel distances. Second, based on the magnitudes of standardized total effects, several urban form factors at tour destinations affect travel distances more than they do at tour origins, including resident density, non-retail density, bus stop density, and job-population index. Third, while some urban form variables may not affect the travel distances directly, they have indirect effects on the travel distances through the activity-travel patterns.

This research is not without limitations. One limitation is related to self-selection effects. Since this study uses cross sectional household travel survey data without any individual attitudinal information, the ability to estimate the impacts of self-selection at tour origins and destinations is limited. Despite the limitation, this research gains additional understanding on the interconnection among travel behavior. The model results also show strong evidence in favor of using urban form to explain travel behavior not only around tour origins but also around tour destinations. Furthermore, the analysis provides important implications for transportation and land use planning. The land use regulation or urban form modification can be used as a tool to change individuals' travel behavior, which will further mitigate the negative externalities related to transportation system.

This study can be extended along different directions. Future work could consider the influence of activity-travel patterns on other travel behavior at aggregate level. A natural follow up would be the investigation of how activity-travel patterns affect the travel demand and VMT at personal and household level, controlling for corresponding socio-demographics and residential urban from characteristics.

\section{$9 \quad$ Acknowledgments}

The authors would like to thank Ms. Rebekah Anderson of ODOT for providing the travel survey datasets and two anonymous reviewers for their critical comments on earlier versions of the paper. 


\section{References}

Akar, G., Chen, N., \& Gordon, S. I. (2016). Influence of neighborhood types on trip distances: Spatial error models for central Ohio. International Journal of Sustainable Transportation, 10, 284-293.

Antipova, A., \& Wang, F. (2010). Land use impacts on trip-chaining propensity for workers and nonworkers in Baton Rouge, Louisiana. Annals of GIS, 16, 141-154.

Bhat, C. R. (1997). Work travel mode choice and number of non-work commute stops. Transportation Research Part B: Methodological, 31, 41-54.

Bricka, S. G. (2008). Trip chaining, linking the influences and implications. Austin, Texas: University of Texas at Austin.

Brownstone, D., \& Golob, T. F. (2009). The impact of residential density on vehicle usage and energy consumption. Journal of Urban Economics, 65, 91-98.

Byrne, B. M. (2013). Structural equation modeling with AMOS: Basic concepts, applications, and programming. Abingdon-on-Thames, UK: Routledge.

Chandrasekharan, B., \& Goulias, K. G. (1999). Exploratory longitudinal analysis of solo and joint trip making using the Puget Sound transportation panel. Transportation Research Record, 1676, 77-85.

Dieleman, F.M., Dijst, M., \& Burghouwt, G. (2002). Urban form and travel behavior: micro-level household attributes and residential context. Urban Studies, 39, 507-527.

Duncan, M. (2015). How much can trip chaining reduce VMT? A simplified method. Transportation, 43(643), $1-17$.

Elldér, E. (2014). Residential location and daily travel distances: The influence of trip purpose. Journal of Transport Geography, 34, 121-130.

Ewing, R., \& Cervero, R. (2001). Travel and the built environment: A synthesis. Transportation Research Record, 1780, 87-114.

Ewing, R., \& Cervero, R. (2010). Travel and the built environment. Journal of the American Planning Association, 76, 265-294.

Ewing, R., Greenwald, M., Zhang, M., Walters, J., Feldman, M., Cervero, R., Frank, L., \& Thomas, J. (2011). Traffic generated by mixed-use developments—six-region study using consistent built environmental measures. Journal of Urban Planning and Development, 137, 248-261.

Frank, L., Bradley, M., Kavage, S., Chapman, S., Lawton, T. K. (2008). Urban form, travel time, and cost relationships with tour complexity and mode choice. Transportation, 35, 37-54.

Ho, C., \& Mulley, C. (2013a). Incorporating intra-household interactions into a tour-based model of public transport use in car-negotiating households. Transportation Research Record, 2343, 1-9.

Ho, C., \& Mulley, C. (2013b). Tour-based mode choice of joint household travel patterns on weekend and weekday. Transportation, 40, 789-811.

Ho, C., \& Mulley, C. (2015). Intra-household Interactions in tour-based mode choice: The role of social, temporal, spatial and resource constraints. Transport Policy, 38, 52-63.

Holzapfel, H. (1986). Trip relationships in urban areas. Brookfield, Vermont: Gower Publishing.

Hu, L. T., \& Bentler, P. M. (1999). Cutoff criteria for fit indexes in covariance structure analysis: Conventional criteria versus new alternatives. Structural Equation Modeling: A Multidisciplinary Journal, $6,1-55$.

Kitamura, R., \& Susilo, Y. O. (2005). Is travel demand insatiable? A study of changes in structural relationships underlying travel. Transportmetrica, 1, 23-45.

Krizek, K. J. (2003). Neighborhood services, trip purpose, and tour-based travel. Transportation, 30, $387-410$.

Kuppam, A. R., \& Pendyala, R. M. (2001). A structural equations analysis of commuters' activity and travel patterns. Transportation, 28, 33-54. 
Lin, T., \& Wang, D. (2014). Social networks and joint/solo activity-travel behavior. Transportation Research Part A: Policy and Practice, 68, 18-31.

Liu C. (2012). Exploring the influence of urban form on travel and energy consumption, using structural equation modeling. College Park, Maryland: University of Maryland.

Liu, C., \& Shen, Q. (2011). An empirical analysis of the influence of urban form on household travel and energy consumption. Computers, Environment and Urban Systems, 35, 347-357.

Lu, X., \& Pas, E. I. (1999). Socio-demographics, activity participation and travel behavior. Transportation Research Part A: Policy and Practice, 33, 1-18.

McDonald, N. (2006). Exploratory analysis of children's travel patterns. Transportation Research Record, $1977,1-7$.

McDonald, N. C. (2005). Does residential density affect the travel "gender gap." Conference Proceedings 35: Research on Women's Issues in Transportation, 68-75.

McGuckin, N., \& Murakami, E. (1999). Examining trip-chaining behavior: Comparison of travel by men and women. Transportation Research Record, 1693, 79-85.

Mercado, R., \& Páez, A. (2009). Determinants of distance traveled with a focus on the elderly: A multilevel analysis in the Hamilton CMA, Canada. Journal of Transport Geography, 17, 65-76.

Morency, C., Paez, A., Roorda, M. J., Mercado, R., \& Farber, S. (2011). Distance traveled in three Canadian cities: Spatial analysis from the perspective of vulnerable population segments. Journal of Transport Geography, 19, 39-50.

Mueller, R., \& Hancock, G. (2010). Structural equation modeling. The reviewer's guide to quantitative methods in the social sciences, 371-383.

Noland, R. B., \& Thomas. J. V. (2007). Multivariate analysis of trip-chaining behavior. Environment and Planning B: Planning and Design, 34, 953.

Pearl, J. (2000) Causality: Models, reasoning and inference. Cambridge, England: Cambridge University Press.

Primerano, F., Taylor, M. A., Pitaksringkarn, L., \& Tisato, P. (2008). Defining and understanding trip chaining behavior. Transportation, 35, 55-72.

Rentziou, A., Gkritza, K., \& Souleyrette, R. R. (2012). VMT, energy consumption, and GHG emissions forecasting for passenger transportation. Transportation Research Part A: Policy and Practice, 46, 487-500.

Schermelleh-Engel, K., Moosbrugger, H., \& Müller, H. (2003). Evaluating the fit of structural equation models: Tests of significance and descriptive goodness-of-fit measures. Methods of Psychological Research Online, 8, 23-74.

Schmöcker, J.-D., Quddus, M. A., Noland, R. B., \& Bell, M. G. H. (2005). Estimating trip generation of elderly and disabled people: Analysis of London data. Transportation Research Record, 1924, 9-18.

Schmöcker, J.-D., Su, F., \& Noland, R. B. (2010). An analysis of trip chaining among older London residents. Transportation, 37, 105-123.

Srinivasan, S., \& Bhat, C. R. (2008). An exploratory analysis of joint-activity participation characteristics using the American time use survey. Transportation, 35, 301-327.

Sun, Y., Waygood, E., Fukui, K., \& Kitamura, R. (2009). Built Environment or Household Life-Cycle Stages-Which Explains Sustainable Travel More? Transportation Research Record, 2135, 123-129.

Susilo, Y. O., \& Kitamura, R. (2008). Structural changes in commuters' daily travel: The case of auto and transit commuters in the Osaka metropolitan area of Japan, 1980-2000. Transportation Research Part A: Policy and Practice, 42, 95-115.

Tillberg Mattsson, K. (2002). Children's (in)dependent mobility and parents' chauffeuring in the town and the countryside. Tijdschrift voor economische en sociale geografie, 93, 443-453. 
Van Acker, V., \& Witlox, F. (2010). Car ownership as a mediating variable in car travel behavior research using a structural equation modelling approach to identify its dual relationship. Journal of Transport Geography, 18, 65-74.

Van Acker, V., \& Witlox, F. (2011). Commuting trips within tours: How is commuting related to land use? Transportation, 38, 465-486.

van den Berg P, Arentze, T., \& Timmermans, H. (2013). A path analysis of social networks, telecommunication and social activity-travel patterns. Transportation Research Part C: Emerging Technologies, 26, 256-268.

Vovsha, P., \& Petersen, E. (2005). Escorting children to school: Statistical analysis and applied modeling approach. Transportation Research Record 1921, 131-140.

Vovsha. P., Petersen, E., \& Donnelly, R. (2003). Explicit modeling of joint travel by household members: Statistical evidence and applied approach. Transportation Research Record, 1831, 1-10.

Wallace. B., Barnes, J., \& Rutherford, G. (2000). Evaluating the effects of traveler and trip characteristics on trip chaining, with implications for transportation demand management strategies. Transportation Research Record, 1718, 97-106.

Wang, R. (2014). The stops made by commuters: evidence from the 2009 US National Household Travel Survey. Journal of Transport Geography, 47, 109-118.

Waygood, E. O. D. (2011). What is the role of mothers in transit-oriented development? The case of Osaka-Kyoto-Kobe, Japan. Transportation Research Board Conference Proceedings.

Wilhelm, J., Wolf, J., Kang, E., \& Taylor, D. (2014, January). The Cleveland GPS Household Travel Survey: Survey design, imputation of trip characteristics, and secondary uses of the data. Paper presented at the Transportation Research Board 93rd Annual Meeting, Washington, DC.

Xiao, X. (2013). Structural equation modeling compared with ordinary least squares in simulations and life insurers' data. Master of science in statistics report. University of Texas at Austin. Retrieved from http://hdl.handle.net/2152/22516

Yang, M., Wang, W., Ren, G., Fan, R., Qi, B., \& Chen, X. (2010). Structural equation model to analyze socio-demographics, activity participation, and trip chaining between household heads. Transportation Research Record, 2157, 38-45. 